\title{
sciendo
}

ACTA UNIVERSITATIS CIBINIENSIS - TECHNICAL SERIES

Vol. 712019

\section{IMPROVEMENT OF THE NATIONAL RESEARCH, DEVELOPMENT AND INNOVATION STRATEGY 2014-2020 IN COMPARISON WITH THE NATIONAL RESEARCH, DEVELOPMENT AND INNOVATION STRATEGY 2007-2013}

\author{
Ana Maria Alecusan \\ University Politehnica of Bucharest, 313 Splaiul Independentei, 060021, Bucharest, Romania \\ Andrei Dimitrescu \\ University Politehnica of Bucharest, 313 Splaiul Independentei, 060021, Bucharest, Romania \\ George Adir \\ University Politehnica of Bucharest, 313 Splaiul Independentei, 060021, Bucharest, Romania
}

\begin{abstract}
The European Union regularly develops research, development, innovation (RDI) strategies for seven years for member countries. Romania benefited from the first RDI strategy during the period 2000-2007, during which our country was trying to meet the conditions of EU accession. Romania is a member of the EU since 1st January 2007 and started, based on the EU's RDI strategy, to develop its own strategy. The present paper aims to analyze the achievement of the general and specific objectives established by National Strategy for Research, Development and Innovation (NSRDI) 2007-2013, the evolution of the results 2014-2017 and what could be the measures and programs taken by Romania in 2019-2020 to bring our country closer to achieving the established objectives through NSRDI for the period 2014-2020.
\end{abstract}

\section{Introduction}

Romania started to prepare for the EU accession many years before 2007. Regarding the National Strategy for Research, Development and Innovation (NSRDI), 2005 the National Agency for Scientific Research began the first steps to prepare the strategy. The principal actors were identified as research institutes, universities, academies, companies, professional and employers' associations, NGOs and representatives of public administration. Questionnaires were designed, sent and centralized. First drafts were public debated. All these activities generated the final version of the what is known as NSRDI 20072013 and publish in January 2007. The guidelines were set to position Romania alongside the other EU countries. [1]

The NSRDI was structured as followed, an introduction that is also an argument for elaborating the strategy, an international and intern analyze of the context, the vision, the objectives, priority areas, innovation, the strategy implementation. Every single objective could be measured and annual reports were going to verify the achievement of the objectives by monitoring the performance indicators.[2]

The identified priority areas were the information society, energy, environment, health, agriculture, food safety and security, biotechnologies, materials, processes and innovative products, space and security, socio-economic and humanistic research.

\section{Method and Results}

Each national strategy for research, development and innovation is verified by the achievement of the performance indicators set by each specific objective. We have read both strategies and tried to verify the fulfillment of these established performance indicators. We have chosen a few of these indicators for Romania, some of the in comparison with other countries in the European Union (EU). The three performance indicators chosen were the gross domestic expenditure on research, development and innovation - how much money dose the state invest in this area, number of employees in the research and development area - how many people work in these area, and the number of patents registered, one of the most eloquent and visible product protected in this area.

\subsection{Gross domestic expenditure on research, development and innovation}


The European Union is making efforts to reduce the economic growth gap with the US and has proposed $3 \%$ from gross domestic product (GDP) for RDI. The EU could not achieve this indicator 2007-2013, and set the same goal for 2020. Romania set 1\% from GDP to achieve until 2013, our country could not achieve this goal not even in 2017, as you can see in the table 1. Only Finland and Sweden maintained a 3\% expenditure between 2007-2017. Austria achieved this percentage 2014, Denmark -2015 and Germany 2017. As it seems, Romania cannot achieve 1\% GDP expenditure for RDI not even in 2020.

Table 1. Gross domestic expenditure on research, development and innovation (percentage from gross domestic product) source: eurostat [4].

\begin{tabular}{|l|l|l|l|l|l|l|l|l|l|l|l|}
\hline geoltime & $\mathbf{2 0 0 7}$ & $\mathbf{2 0 0 8}$ & $\mathbf{2 0 0 9}$ & $\mathbf{2 0 1 0}$ & $\mathbf{2 0 1 1}$ & $\mathbf{2 0 1 2}$ & $\mathbf{2 0 1 3}$ & $\mathbf{2 0 1 4}$ & $\mathbf{2 0 1 5}$ & $\mathbf{2 0 1 6}$ & $\mathbf{2 0 1 7}$ \\
\hline EU (28) & 1.77 & 1.83 & 1.93 & 1.92 & 1.97 & 2 & 2.02 & 2.03 & 2.04 & 2.04 & 2.07 \\
\hline Belgien & 1.84 & 1.92 & 1.99 & 2.05 & 2.16 & 2.27 & 2.33 & 2.39 & 2.46 & 2.55 & 2.58 \\
\hline Bulgarien & 0.43 & 0.45 & 0.49 & 0.56 & 0.53 & 0.6 & 0.64 & 0.79 & 0.96 & 0.78 & 0.75 \\
\hline Tschechien & 1.3 & 1.24 & 1.29 & 1.34 & 1.56 & 1.78 & 1.9 & 1.97 & 1.93 & 1.68 & 1.79 \\
\hline Dänemark & 2.52 & 2.77 & 3.06 & 2.92 & 2.94 & 2.98 & 2.97 & 2.91 & $\mathbf{3 . 0 6}$ & $\mathbf{3 . 1}$ & $\mathbf{3 . 0 5}$ \\
\hline Germany & 2.45 & 2.6 & 2.72 & 2.71 & 2.8 & 2.87 & 2.82 & 2.87 & 2.91 & 2.92 & $\mathbf{3 . 0 2}$ \\
\hline Estland & 1.07 & 1.26 & 1.4 & 1.58 & 2.31 & 2.12 & 1.72 & 1.43 & 1.47 & 1.25 & 1.29 \\
\hline Lettland & 0.55 & 0.58 & 0.45 & 0.61 & 0.7 & 0.66 & 0.61 & 0.69 & 0.63 & 0.44 & 0.51 \\
\hline Litauen & 0.8 & 0.79 & 0.83 & 0.78 & 0.9 & 0.89 & 0.95 & 1.03 & 1.04 & 0.84 & 0.89 \\
\hline Luxemburg & 1.59 & 1.62 & 1.68 & 1.5 & 1.46 & 1.27 & 1.3 & 1.26 & 1.28 & 1.3 & 1.26 \\
\hline Ungarn & 0.96 & 0.98 & 1.13 & 1.14 & 1.19 & 1.26 & 1.39 & 1.35 & 1.36 & 1.2 & 1.35 \\
\hline Austria & 2.42 & 2.57 & 2.6 & 2.73 & 2.67 & 2.91 & 2.95 & $\mathbf{3 . 0 8}$ & $\mathbf{3 . 0 5}$ & $\mathbf{3 . 1 3}$ & $\mathbf{3 . 1 6}$ \\
\hline Polen & 0.56 & 0.6 & 0.66 & 0.72 & 0.75 & 0.88 & 0.87 & 0.94 & 1 & 0.96 & 1.03 \\
\hline Rumänien & 0.51 & 0.55 & 0.44 & 0.46 & 0.5 & 0.48 & 0.39 & 0.38 & 0.49 & 0.48 & 0.5 \\
\hline Slowenien & 1.42 & 1.63 & 1.82 & 2.06 & 2.42 & 2.57 & 2.58 & 2.37 & 2.2 & 2.01 & 1.86 \\
\hline Slowakei & 0.45 & 0.46 & 0.47 & 0.62 & 0.66 & 0.8 & 0.82 & 0.88 & 1.17 & 0.79 & 0.88 \\
\hline Finnland & $\mathbf{3 . 3 5}$ & $\mathbf{3 . 5 5}$ & $\mathbf{3 . 7 5}$ & $\mathbf{3 . 7 3}$ & $\mathbf{3 . 6 4}$ & $\mathbf{3 . 4 2}$ & $\mathbf{3 . 2 9}$ & $\mathbf{3 . 1 7}$ & $\mathbf{2 . 8 9}$ & $\mathbf{2 . 7 4}$ & $\mathbf{2 . 7 6}$ \\
\hline Schweden & $\mathbf{3 . 2 5}$ & $\mathbf{3 . 4 9}$ & $\mathbf{3 . 4 5}$ & $\mathbf{3 . 2 1}$ & $\mathbf{3 . 2 5}$ & $\mathbf{3 . 2 8}$ & $\mathbf{3 . 3}$ & $\mathbf{3 . 1 4}$ & $\mathbf{3 . 2 6}$ & $\mathbf{3 . 2 7}$ & $\mathbf{3 . 4}$ \\
\hline UK & 1.62 & 1.62 & 1.68 & 1.66 & 1.66 & 1.59 & 1.64 & 1.66 & 1.67 & 1.68 & 1.66 \\
\hline
\end{tabular}

\subsection{Number of employees from research and development}

Another performance indicator is the number of scientists. According to table 2, in Romania the number of employees from RD units did not increase, quite the contrary. No information were available for the years after 2016. We can conclude that the RD sector is not attractive and this is why the number of researchers is sinking.

Table 2. Employees from research - development units in Romania, by sectors of performance and type of ownership at the end of year, source: eurostat. [5]

\begin{tabular}{|l|l|l|l|l|l|l|l|l|l|l|}
\hline sectltime & $\mathbf{2 0 0 7}$ & $\mathbf{2 0 0 8}$ & $\mathbf{2 0 0 9}$ & $\mathbf{2 0 1 0}$ & $\mathbf{2 0 1 1}$ & $\mathbf{2 0 1 2}$ & $\mathbf{2 0 1 3}$ & $\mathbf{2 0 1 4}$ & $\mathbf{2 0 1 5}$ & $\mathbf{2 0 1 6}$ \\
\hline Total & 30740 & 30864 & 30645 & 30707 & 25489 & 27838 & 27600 & 27535 & 27253 & 27801 \\
\hline $\begin{array}{l}\text { Business } \\
\text { sector }\end{array}$ & 7971 & 6623 & 6389 & 6182 & 4122 & 5451 & 5738 & 5848 & 4923 & 5402 \\
\hline $\begin{array}{l}\text { Government } \\
\text { sector }\end{array}$ & 6100 & 6541 & 6010 & 5831 & 6117 & 6664 & 6859 & 6799 & 7032 & 7043 \\
\hline $\begin{array}{l}\text { Tertiary } \\
\text { education } \\
\text { sector }\end{array}$ & 16510 & 17579 & 18137 & 18540 & 15086 & 15569 & 14884 & 14743 & 15057 & 15083 \\
\hline $\begin{array}{l}\text { Private } \\
\text { non profit } \\
\text { sector }\end{array}$ & 159 & 121 & 109 & 154 & 164 & 154 & 119 & 145 & 241 & 273 \\
\hline \multicolumn{2}{|l}{} & & & & & & & & & \\
\hline
\end{tabular}

\subsection{Number of patents}

Because innovation and the protection of the invention is not important, the number of patent applications is not high. As in Figure 1 shown, the goal mentioned in the NSRDI of increasing three times the number of applications in 2013 compared to 2006 was not achieved. It is to be mentioned that it lasts almost two years to obtain a patent from the appliance to the grant. 


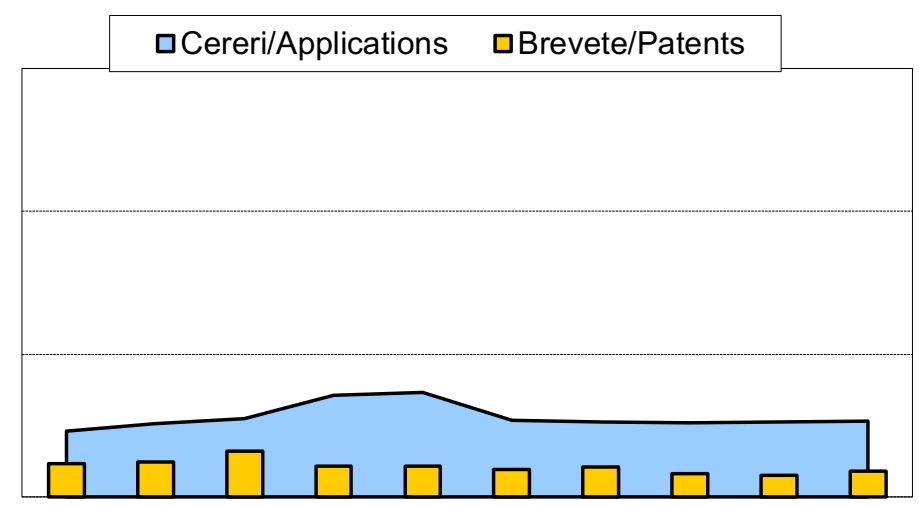

Fig. 1. Filed patent applications and patents granted by the State Office for Inventions and Trademarks (SOIT) in the period 2007 $-2016[3,9]$

3. The Objectives of the NSRDI

Because the strategies are documents of few pages, we considered relevant to create a table not to write a story about the changes of the objectives. To have a better and an simple view on the strategic specific objectives of the two strategies for RDI, we compound Table 3

Table 2. Formatting sections, subsections and subsubsections.

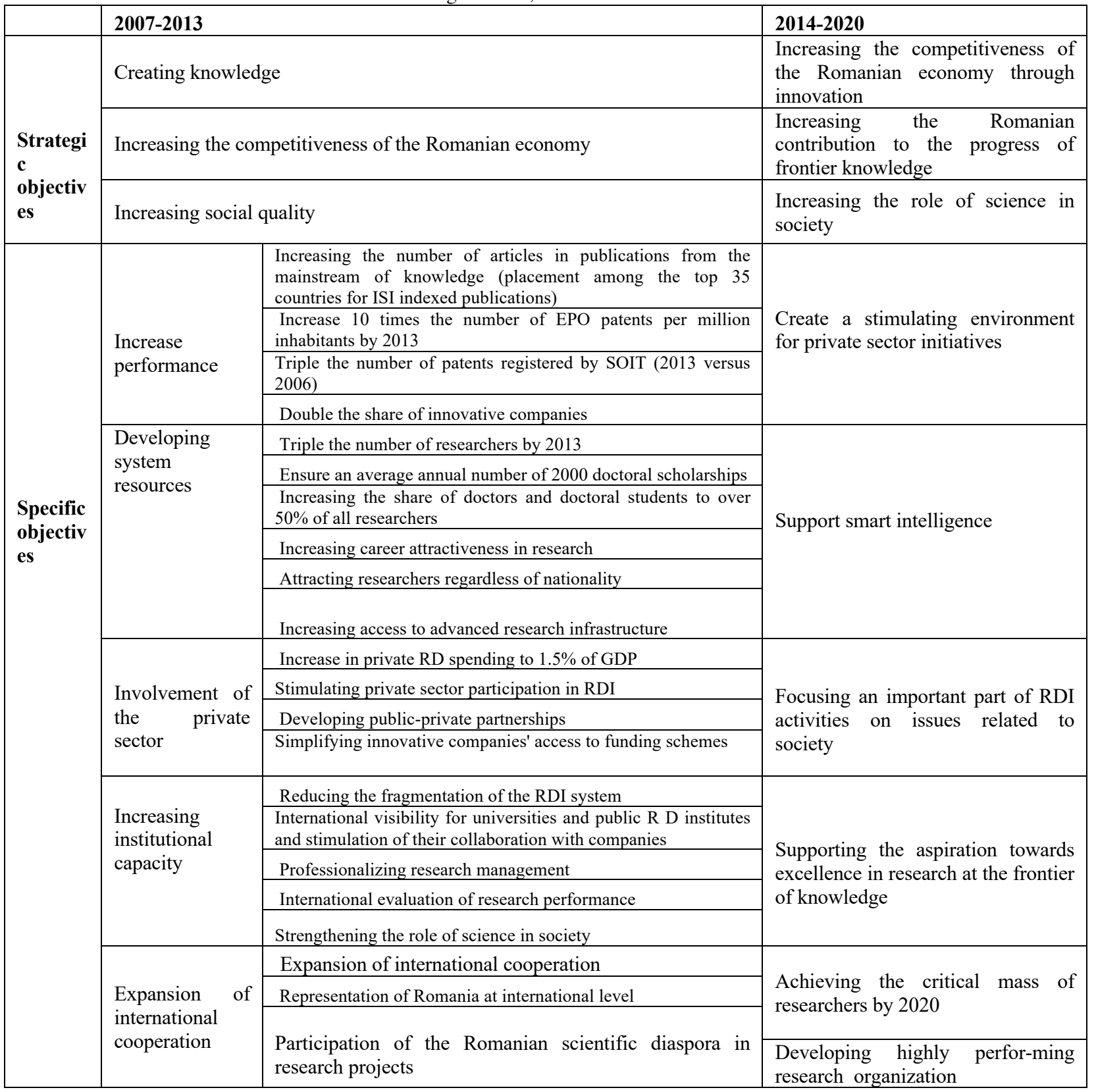


We did not intend to analyze the text, but we noticed differences in the formulation of the objectives, differences that are obvious. As you can notice, the strategy 2007-2013 had also performance indicators for each specific objective, that could be measured and evaluated. The strategy 2014-2020 has no performance indicators, is more theoretical and can hardly be evaluated by practical means. Even the priority or strategic areas are clearly defined and can be identified easily in the first strategy for Romania. The areas are almost the same in both strategies. [6,7]

\title{
4. Conclusions
}

It is to be mentioned that the paper analyzed only a few performance indicators, but enough to show that the estimated values have not been reached.

Analyzing all the indicators would have led to a considerable extent of the paper. Difficult and non-centralized access to data has made it harder to write the paper, this is why we propose to create a database with all information about NSRDI. An easy access to this information on a website can stimulate actors on the RDI market to apply for finance a RDI project.

A huge step was done regarding the project financing by introducing new financing programs including start-up financing. http://www.finantare.ro/etichete/fonduri-cercetare is one of the websites with information about financing RDI projects. https:/www.uefiscdi.ro/ is another website with many information. On this site are missing the annual, intermediate and final reports for each RDI strategy, reports that could offer transparence for each part of the strategy. The strategy 2014-2020 is poorer than the previous one. We cannot notice an improvement, it is rather a regress. 2007-2013 the strategy was enough to have an image of the strategy, their objectives and the fulfillment of these by performance indicators, 2014-2020 the national plan for research, development and innovation contained more information than the strategy itself.

A forecast for one of the performance indicator analyzed in the paper is useless because between 2007-2017 there were not registered any significant deviations from the downward trend or stagnation. A better transparency, more publicity and economic and social advantages could change the trend.

\author{
Abbreviations \\ RDI - research, development and innovation \\ EU - European Union \\ NSRDI - National Strategy for Research, Development and Innovation \\ $\mathrm{NGO}$ - non-governmental organization \\ GDP - gross domestic product \\ $\mathrm{RD}$ - research and development \\ SOIT - State Office for Inventions and Trademarks \\ EPO - European Patent Office \\ ISI - Institute for Scientific Information
}

\section{References}

1. http://statistici.insse.ro:8077/tempo-online/\#/pages/tables/insse-table

2. https://sciencebusiness.net/search?search_api_fulltext=innovation\&sort_by=created\&s ort_order $=$ DESC\&page $=1$

3. A.M.Alecusan, A.Dimitrescu, Innovation management: the past, present and future of the market, Studies in Business and Economics, vol.11, Issue 3, (2016), ISSN 1842-4120, pages 140-149, WOS: 000449721900011

4. http://discutii.mfinante.ro/static/10/Mfp/Prezentarebuget2019.pdf?fbclid=IwAR3RQojjRyXf5QkYfVtPYDLGkL0HBraQNzz72Jk75mzKkBu8V-fTCNUqU

5. http://appsso.eurostat.ec.europa.eu/nui/setupDownloads.do

6.https://ec.europa.eu/eurostat/tgm/refreshTableAction.do?tab=table\&plugin=1\&pcode=tsc00003\&langu age $=$ de

7. https://ec.europa.eu/eurostat/documents/2995521/8493775/9-01122017-APDE.pdf/bf29530b-e495-

4ad0-a889-f9e278ef1c85

8. http://www.ad-astra.ro/journal/8/florian_oamenii_de_stiinta.pdf

9. http://statistici.insse.ro:8077/tempo-online/\#/pages/tables/insse-table 